geordneten Lattmann und Behrens, betr. Reform des Patentgesetzes in der Sitzung des Reichstages vom 21./4. 1909. Der Antrag lautete: Der Reichstag wolle beschließen, den Herrn Reichskanzler zu ersuchen, bei der bevorstehenden Reform des Patentgesetzes in dasselbe Bestimmungen aufzunehmen, durch die die Erfindungen der technischen Angestellten und Arbeiter diesen in geistiger und materieller Beziehung mehr als bisher geschützt werden. An der Beratung beteiligten sich die Abgeordneten Lattmann, Dove, Junck, Na cken, Frank. Der Antrag wurde einstimmig angonommen (202-211).

Albert Bolze. Aus dem Patentrecht. - Johannes Mittelstädt. Das Recht des Erfinders. - Adalbert Diringer. Richter und Rechtspreehung. Diese Abhandlungen bilden einen Teil der Festschrift, die die juristische Gesellschaft in Leipzig der Universität Leipzig zur 500jährigen Jubelfeier widnete. In der $\mathrm{D}$ ü $\mathrm{r}$ i n ge r schen Abhandlung wird auch die Frage der technischen Richter, die auf der Leipziger Tagung (1908) des deutschen Vereins für den Schutz des gewerblichen Eigentums so lebhaft erörtert wurde, berührt. Verf. bekennt sich als Gegner der Laienrichter, allerdings unter der irrigen Voraussetzung, daß es sich um technische Berufsrichter handele $(417-422)$.

\section{Erzeugung fester Metallniederschläge durch Spritzung nach Schoop.}

Von Dipl.-Ing. Erich Schnechenbera, Berlin.

(Eingeg. 8.76. 1910.)

Das Verfahren scheint der Galvanoplastik in mancher Hinsicht überlegen zu sein. Geschmolzenes Metall wird von hochgespannten und erhitzten Gasen oder Dümpfen durch eine geeignete Düse getrieben und als feiner Staub gegen den mit Metall zu überziehenden Gegenstand geschleudert oder gegen ein die gewünschte Form der Metallwand tragendes Hilfsmodell aus beliebigem Material. Zur Spritzung von Metallen, die leicht oxydieren, eignet sich Wasserstoff oder Stickstoff oder quch überhitzter Wasserdampf. Das flüssige Metall tritt unter dem hohen Druck von $20-25 \mathrm{~kg} / \mathrm{qcm}$ aus der Düse, löst sich dabei zu ganz feinem Pulver oder Nebel auf und fliegt mit außergewöhnlich hoher Geschwindigkeit (bis zu $25 \mathrm{~km} / \mathrm{sek}$ ) auf den zu behandelnden Gegenstand. Die Nebeltröpfchen schlagen sich infolgedessen als äußerst dünnes und festes Häutchen nieder mit hervorragend gleichmäßigem, amorphem Gefüge und glattem Aussehen. Die Dicke des Häutchens beträgt im Augenblick $0,02 \mathrm{~mm}$; bei längerer Spritzdauer beliebig mehr. Häutchen von $6 \mathrm{~mm}$ Dicke entstehen innerhalb 8-10 Sekunden.

Die Temperatur der Metallnebel ist nur 10-60 $60^{\circ}$, weil infolge der Expansion des hochgespannten Gases in der Düsenmiündung eine ganz bedeutende Frniedrigung der Temperatur des flüssigen Metalles eintritt; sie beträgt etwa $250-300^{\circ}$. Für das Spritzverfahren eignen sich besonders die dünnflüssigen Metalle, wie Zinn, Blei, Kupfer und Aluminiumlegierungen. Als spezifisches Gewicht fand man bei Bleiniederschlägen 9,i, wenn überhitzter Wasser- dampf, 11,0 und 11,3, wenn Wasserstoffgas benutzt wurde bei sonst gleichen Verhältnissen.

Durch die Spritzung können jetzt auch festo Niederschläge aus Aluminium erhalten werden, was ja bisher der Galvanoplastik nicht gelang. Ein weiterer Vorzug ist der, daß die Oberflächen der zu überziehenden Gegenstände nicht, wie beim galvanischen Verfahren, elektrisch leitend zu sein brauchen; auch können sie, weil die Metallnebel nicht heiß sind, aus schmelzbaren und entzündbaren Stoffen bestehen. Es läßt sich also jeglicher Gegenstand ohne weiteres mit Metall überziehen, auch Gips, Hartgummi, Celluloid. Ton, Glas, Holz, Wachs, Pappe, Papier, Gewebestoffe. Zur Herstellung von Hohlkörpern bedarf es nur eines einfachen Papier- oder Pappmodells. Als ein Beispiel für die Leistungsfähigkeit sei erwähnt, $d a ß$ es bereits gelungen ist, von einem und demselben Negativklischee innerhalb zehn Stunden bis zu 300 Positirklischees herzustellen, die sich von echten "Galvanos" durch nichts unterscheiden, außer durch die Herstellungskosten.

[A. 128.]

\section{Zusatz za dem Artikel: "Neuer Sicherheitsheber" ").}

(Eingeg. d. 24./5. 1910.)

Den yon mir beschriebenen Sicherheitsheber habe ich in der Weise verbessert, $\operatorname{da} B$ derselbe auch zum Absaugen von klaren, über Niederschlägen befindlichen Füssigkeiten verwandt werdeu kann, ohne die Niederschläge aufzurühren.

Die Verbesserung besteht in einem ca. 10 bis $12 \mathrm{~cm}$ langen Rohr von der Weite des entsprechenden Heberrohres; dasselbe ist an einem Ende zugeschmolzen und vom zugeschmolzenen Teil an mit Löchern versehen, die immer $1 \mathrm{~cm}$ voneinander entfernt sind. Das Rohr wird mit dem Heberrohr unter Einschaltung einer zur Befestigung dienenden Glasröhre durch Gummischlauch verbunden. Die einzelnen Löcher können durch Uberschieben resp. Abschieben von Gummischlauchringen geschlossen resp. geöffnet werden.

Soll nun eine Flüssigkeit über einen Niederschlag abgesaugt werden, so mißt man die Höhe des Niederschlages außerhalb dess Gefäßes am Heber ab und öffnet das der Höhe des Niederschlages entsprechende Loch am Heberrohr, während man alle andern Löcher durch Úberschieben der zugehörigen Gummiringe verschließt. Alsdann wird der so präpurierte Heber vorsichtig bis auf den Boden des Gefäßes getaucht und nach vorherigem Schließen des Hebers angesaugt.

Man ist so in der Lage, jede über Niederschlägen von beliebiger Höhe befindliche Flüssigkeit abzusaugen, ohne den Niederschlag aufzurühren, und erspart sich auf diese Weise das langsame Filtrieren.

Um die Flüssigkeit möglichst vollkommen über dem Niederschlag absaugen zu können, ist es angebracht, daß Gefäß so schräg zu stellen. daß der Niederschlag knapp an das geöffnete Loch des Heberrohres heranlangt.

1) Diese Z. 23, 20 (1910), 